\title{
Changing Occupational Roles in Audit Society-The Case of Swedish Student Aid Officials
}

\section{Anders Bruhn}

Professor in Social Work, School of Law, Psychology and Social Work, Örebro University, Sweden ${ }^{1}$

\begin{abstract}
This article is about occupational change concerning a non-professional group of Street Level Bureaucrats - student aid officials at the Swedish Board for Study Support (SBSS). The aim is to describe and analyze changes in their occupational role - their discretional space and working conditions under the impact of changed ways to manage public service organizations and new information and communication technology. The SBSS is the sole administrator of student financial aid in Sweden. Its officials investigate and take decisions about students' applications and repayment of loans. This work includes interacting with clients via telephone and computer. These officials have to have a certain amount of discretion to interpret and apply rules and regulations on specific circumstances in individual cases. How are their working conditions affected by organizational and policy changes in the authority? How is their ability to exercise influence and control over their own work performance affected? The analysis highlights how officials suffer from decreased discretion and an increasing routinization in their work. This is a result of a regulatory framework continuously growing in detail together with increasing management control based on new information and communication technology. What remains of discretion is a kind of 'task' discretion, the ability to do minor technical manipulations of rules in individual cases. Even today's top management seems critical of this development. Besides further automatization and reduction of staff an ongoing process of organizational change is therefore also aiming to develop officials' competence and working conditions toward what may be seen as organizational professionalism, a development of specific occupational skills and a discretion adjusted and subordinated to managerial means and ends. The analysis rests on data from a research project (2011 to 2014) about Institutional Talk. Data sources are qualitative interviews, audio-taped speech sequences, observational field notes, and official documents.
\end{abstract}

\section{KEY WORDS}

Street Level Bureaucrats / Discretion / Occupational roles / Occupational change / NPM / New Public Management / ICT / Information and Communication Technology / Public Service occupations

\section{Introduction}

he extensive proliferation of changes and reforms in recent decades concerning the mission and the governance of public service work has led to comprehensive research about consequences for different occupational groups in the sector (e.g. Barton 2008, Bejerot \& Hasselbladh 2003, Bezes et al. 2012, Evans 2010, Evetts 2009). Much research about how new principles for governance affect occupational roles has focused on professional or semi-professional groups, such as doctors, nurses, teachers, and social workers (Dahl 2009, Höjer \& Forkby 2010, Stenlås 2011). Empirical research about

\footnotetext{
${ }^{1}$ E-mail: anders.bruhn@oru.se
} 
how different 'non-professional' public service occupations are exposed to this managerial shift is not as developed. This article is about a non-professional group of Street Level Bureaucrats (SLBs). I will describe and analyze changes in their occupational role-in their discretional space and working conditions under the impact of changed ways to manage public service organizations and new information and communication technology (ICT). The empirical case is student aid officials working at the Swedish Board for Study Support (SBSS).

Financial support (grants and loans) for higher education is administered by one single public authority in Sweden-the SBSS. Almost a million people received economic support from SBSS in 2011, and the authority holds repayment claims on people who have gone through higher education totaling about 30 billion US dollars. SBSS has around 1000 employees. The vast majority of these belong to the group studied here. As SLBs these officials handle inquiries and make decisions about support, loans, and repayment in individual cases on a daily basis. This requires a certain amount of personal discretion to make judgments and take action concerning, and in interaction with individual clients (Lipsky 1980).

SBSS, originally a product of a social-democratic welfare regime for improved access to higher education, despite social class origin has gone through several changes in the last decades. The theoretical point of departure in this article is that the occupational roles of public service employees of today first and foremost have to be understood in relation to three developmental processes on institutional-level working in interaction. The first one is about changes in the welfare regime concerning the commission for authorities and their underlying political values. In later decades there has been a gradual but clearly visible shift here toward a stronger emphasis on economic values, i.e., efficiency and control of the expenditure of tax revenues (Power 1997). The second process concerns changes in how authorities are governed, changes usually assigned to the umbrella doctrine of New Public Management (NPM; Hood 1991, 1995). This has meant implementation of managerial tools based on two sometimes contradictory logics: the bureaucracy and the market, e.g., increased strictness in rule-following vs. service and flexibility toward the 'customer' (Christensen \& Laegreid 2001). The third process concerns the far-reaching implementation of new ICT. ${ }^{1}$ ICT may be used for job enrichment and increased selfcontrol for employees as well as standardization and increased managerial control of work performance. The task here is how it is used in relation to the other two processes, and how it does affect the occupational role of the officials studied. This case study of SBSS officials may be an illustrative example of how such a reciprocal interaction between developments on different institutional levels drives today's development of the public sector. We may expect them to be quite similar to those confronting bigger SLB groups, such as officials at the Swedish Social Insurance Agency and the Swedish Employment Agency (cf. Melander 2013). The fact that SBSS officials are a relatively small group employed by one and the same agency may make changes more apparent and easy to view as a whole compared to studying bigger and more spread-out groups.

\section{Studying SLBs in Audit Society-a theoretical framework}

\section{Street Level Bureaucrats}

This article is a product of a research project about how civil servants transform formal regulation and develop practical policy in interaction with clients. Lipsky's (1980) 
theory about SLBs has here been a natural take-off. ${ }^{2}$ The concept SLB denotes civil servants responsible for mediating between the state's programmatic policy-making and its citizens. This implies certain autonomy and discretion to act-rules and regulations must be interpreted and translated from their programmatic format to unique situations and applied with consideration for human factors (Lipsky 1980, p. 15). On the basis of this discretion they develop practical policy for how formal rules shall be applied in real situations. This position as policy-makers interpreting and mediating rules in unique cases puts management in a certain position of dependency. Minimizing this dependency, securing that formal regulation is correctly applied, and arbitrariness on behalf of the SLBs are prevented, is a central aim for management (Lipsky 1980, p. 24). How this can be done was Lipsky's task. However, his theory may as well be used from the perspective of employees and clients, i.e., to analyze the discretional scope and preconditions for developing professional skill and knowledge in finding best solutions for clients (Ellis 2011, Evans 2013 Johansson 1992). In working with 'human material,' giving service in interaction with people in need, questions of discretion/control vs. questions of content/ quality in work are intimately related. Experiences of professionalism and quality are produced in the process of relational work, in interaction with 'the other,' the client, patient, etc. These experiences then depend on the freedom of the civil servant to act upon knowledge about the client's needs, desires, and unique circumstances. Reduced discretion may therefore be experienced as a hindrance to fulfill high-quality work performance. On the other hand, meaning and quality in work may also be searched for in the development of professional know-how in applying rules and regulations correctly. How loss of discretion is experienced among different occupational groups may also have to do with whether there exists a certain formal knowledge base, and a common ethics held by the group. Normally there is a difference here between SLB groups with or without status as a profession. The former are normally ascribed a legitimate right, and are expected to control how to use their knowledge. The latter, of which the group studied here is an example, cannot plead for such a right (Evans 2012). This group may in spite of this develop and defend an internal strongly anchored best practice.

\section{Changes in the institutional framework of public service organizations}

The Swedish system for study support originates from values and policies of centrality in the heydays of the social democratic welfare state. To organize these grants and loans as a public service commission for satisfying the growing need for educated labor in a rapidly expanding economy was an important motive. However, the system also rested on fundamental political values: equal opportunities and access to higher education for those with the necessary qualities irrespective of class origin and social status should be guaranteed by the state. A strong state should take action on the basis of scientific knowledge on macro- as well as micro-level for creating equal life chances for all its citizens. Costly public investments in the present were often argued for as strategically supporting societal transformation. And, it was often legitimate to use the same kind of logic in individual treatment and client work (e.g., 'if the client is relieved from amortization payment the coming months she will be able to build up ability to pay regularly in future'). In the end of the eighties but especially after the millennium shift the counterparadigm of neo-liberalism has gained a lot of influence. In relation to general public policy this means a primacy of instrumental values about cost-efficiency at the expense 
of others (Hood 1991, p. 11). It rests on values about small government and tax payers' right to know that their money 'is being spent economically, efficiently, and effectively...' (Power 1997, p. 44). The commission of the state is to uphold the law and the distribution of resources according to principles of equal justice, not welfarist ideals of social engineering and empowerment of 'underdog' individuals or groups. It seems reasonable to assume that this value change has made strong imprints on the commission of the SBSS.

The different means used for governance under the dominance of the neo-liberal values described can be referred to as tools of NPM and its above-mentioned logics for running public service: the market and the bureaucracy. The former logic brings the concept of customer-the client as a buyer in demand of good service. Requirements for good service are high accessibility and efficiency in decisions, but also politeness, flexibility, and treating customers as unique persons. The logic of bureaucracy in certain ways contradicts this. It rather brings inflexibility, strictly treating clients on the basis of formal rules and routines. This may lead to certain dilemmas, especially when it comes to interaction with clients. Further, a typical measure of the market logic is de-centralized responsibility via performance targets and result control. Typical of the bureaucratic logic is centralized control via detailed regulation and tight step-by-step measures for quality assurance. However, in total NPM has brought a long row of far-reaching control methods of employee performance most often built on quantitative techniques, e.g., standardized performance indicators/targets, increased detail in rules and regulation, clearly defined management directives and assignments with highly developed instructions, strict budget control on every level of the organization, and so forth (Christensen and Laegreid 2007, Power 1997). It is often sold-in as a de-centralization but means basically centralization in governance, a return from an earlier honored emphasis on management by culture, and charismatic leadership to the logics of the old machine bureaucracy, the systemic governance via bureaucratic authority (Weber 1922/1983). This time however, it builds on possibilities opened up by new ICT.

It is important to stress that ICT technology is neutral. It does not lead to a certain kind of governance of employees in itself; it is how it is used that matters (Warhurst $\&$ Thompson 2006). However, the kind of fine-grained quantitative measurements requested by NPM are no doubt facilitated by the powerful tools of new ICT. Research that directly addresses the connection between ICT and the different NPM measures in public service is scarce. Schedler and Scharf (2001), however, when pointing at the reciprocal reinforcement of ICT and NPM conclude that the introduction of e-government is a strong factor reinforcing the NPM reform. Its apolitical nature eases its introduction in comparison with the more ideological nature of NPM. Several authors have stressed the enhanced abilities to monitor employee performance via new ICT (Garson 1989). The growing dependency of electronic devices for work performance is also important. Further, automatization via new media changes conditions for social interaction with clients, as well as between employees (Asgarkhani 2007). However, here we have to make a distinction between automation and information. The former leads to standardization and obstruction of professional control (powerlessness) while the latter may stimulate worker self-control because it enhances the possibility to overview complex details (Tummers et al. 2009). Lopéz-Nicolas and Meronõ-Cerdán (2009) make an important distinction when it comes to information-what they term personalization vs. codification of knowledge. Codification means making knowledge generally usable for various purposes-converting intellectual knowledge into structural capital. Stored in 
documents, manuals, databases, electronic repositories, and so forth it becomes independent of employees. Personalization on the other hand means a focus on dialogue between individuals-a person-to-person approach of sharing knowledge. What they call tacit knowledge (implicit knowledge based on experience and praxis) cannot be codified; sharing it requires interaction between workers (p. 212). The codification strategy is typical of the hierarchic cultures of bureaucracy. This distinction between different strategies for knowledge sharing is vital in the present study: How do the enhanced possibilities of informational exchange affect the occupational roles of the officials, and the efficiency and treatment of clients?

\section{SLB working conditions in today's institutional framework}

Now, what kind of working conditions may be expected as a result of an institutional framework like the one sketched here? As discussed above the question of the discretion of SLBs becomes pivotal here. What kind of discretion remains for SLBs to act in accordance with what is valued as professionalism and high quality in work? We cannot presuppose that the 'regulative explosion' of today automatically means reduced SLB discretion (Evans \& Harris 2004). Paradoxically it may sometimes create more of it. The wording of rules is always open-textured. They are by necessity vague. There are always ambiguities and borderline cases, alternative fields of application, and so forth (Evans \& Harris 2004). The situations the rule is meant to cover are never identical. Different rules may often end up in conflict with each other leading to a need for adjustment, balance, and prioritization (Liebling et al. 2011). Taylor and Kelly (2006) discern three different forms of discretion:

1. Value discretion: the ability to act upon norms about professional practice anchored in knowledge, experience, and training.

2. Rule discretion: the ability to interpret and prioritize between vague and contradicting rules and rule systems.

3. Task discretion: the ability and skill to execute prescribed tasks. Even if these are increasingly exposed to control and steering measures, they may be complex and demand discretion on street level.

The authors conclude that a key characteristic of service delivery under NPM systems in the UK has been the encouragement of SLBs to use their discretion to reduce the costs and improve the quality of service 'arguably increasing task discretion for professionals and helping to create an increased awareness of the cost of services' (Taylor \& Kelly 2006, p. 633). This process toward a more task-oriented service also implies more of skill-based training at the expense of knowledge-based education of some professionals. Taylor (2007, p. 560) sees a trend of teachers becoming technicians occupied with teaching skills measured against 'social efficiency' while their 'developmentalist position' as professionals is increasingly being repressed. Ellis (2011) shows how some groups of social workers adjust to the management logic of governance. The discretional scope for developing informal practice is severely reduced because of increasing detailiation of rules in combination with new ICT systems of control. Rules become tools for self-discipline, and the worker becomes a practitioner saluting professionalism in rule-performance, in 
mastering the rule-system in a technical way (cf. Liljegren 2012). Barton (2008) concludes that performance indicators in social work create an 'isomorphic approach' that makes professional innovation, assessment, and autonomy disappear.

However, discretion is neither good nor bad per se. Discretion always exists within a political and ideological context in which the professional group and other social forces operate, and it must be analyzed in relation to that context (Evans \& Harris 2004). Under certain circumstances it may be an important professional attribute. In others it may serve as something for policy-makers to hide behind and/or provide professionals with an opportunity to abuse power. And, of course it must be related to the public policy values that are guiding the commission of the authority. Are changes for the actual group here developing toward a loss of discretion and an impoverishment of job content, toward narrow specialization, isomorphism and routinization? Or, is transformation from one kind of discretion toward another a move toward enhanced qualification in a partly different area? Are these changes necessary for improved authority performance?

\section{Data and Method}

This article is based on data from a research project on Institutional Talk. The aim was to study speech interactions between officials and clients in their institutional framework. The main data source here is 1,400 recordings of telephone calls. These are analyzed by Conversation Analysis (CA, Heritage \& Clayman 2010). A multilevel approach for analyzing the transformation from formal to practical policy in professional-client interactions is presented in a forthcoming article (Bruhn \& Ekström 2014). In this article however, the focus is on the impact of the institutional framework on the scope to act for staff and managers. Main data sources used here are qualitative semi-structured interviews and official documents (programmatic writings, visions, evaluative reports, accounts, and follow-up statistics). Twelve persons were interviewed, eleven of these between May 2011 and December 2012. Respondents were chosen on the basis of theoretical sampling (position, time in service, gender, education; see Strauss 1987). Five ordinary officials at one local office, the chairmen of the two unions' organizing officials, and four top managers at Head Office were interviewed. Four interviewees had 25 years' experience or more in service. This together with document data gave a good picture about the longitudinal change of the authority. A follow-up interview with the new GD of the authority was done in February 2014. All quotes from respondents are presented with fictitious names. The project speech recordings being carefully analyzed for other parts of the project have functioned as a context for validations of facts and interview statements, and for comparisons between data. This goes especially for 76 audio recordings from telephone conversation concerning repayment and repayment plans, one of the most critical incidents where officials' discretion is put to test in daily practice. Interviews, documents, the 76 audio recordings, and some observational field notes were analyzed using meaning categorization. Basically this means sorting into different themes. Themes were constructed in dialogue between data and theory, i.e., some grew out of data, others on the basis of theoretically established concepts (Layder 1998). Analysis rests on a hermeneutical approach interpreting data by a conscious use of different theoretical perspectives (Kvale \& Brinkmann 2008). For handling data, qualitative software NVivo (10) was used. 


\section{The case-some short facts}

When data collection in this project started, SBSS had one Head Office and 13 local offices located in areas with institutions of higher education, and one Call Center located in a small northern town. Head Office houses top management and different support departments, e.g., HR, Statistics, ICT. Every local office had a manager, some also had group managers; 65 per cent of the employed officials were women; mean age of the employees was 43.5 years. Staff turnover was low. An academic degree was not a formal requirement for this position. However, the amount of staff with such degrees has always been quite high. Staff has two union alternatives: a minority belongs to Jusek, a member of the umbrella organization for university graduates (SACO). The majority (even several academics) belongs to ST, a part of the organization for white collar workers (TCO).

During the time of our study a new General Director (GD) was employed. In connection with her taking office an extensive organizational change of the authority was initiated. Since then, three local offices have been closed down, and staff has decreased from 1100 to 900 .

\section{SBSS officials_-occupational roles in a changed institutional framework}

\section{Disposition}

In the first two sections of the analysis below I will describe general changes in the authority's commission as well as organization since the late 1980s. In the following six sections I will deal systematically with how ICT and applied managing techniques affect the occupational role of the officials. In a final section I will briefly discuss the new process of organizational change initiated by the new GD.

\section{The erosion of former welfare values and its impact on the commission of the authority}

The successive shift in Swedish public sector policy from the ideals of a socio-liberal welfare regime to a neo-liberal one has made clear imprints on the commission of SBSS. Today an all-embracing focus on economic efficiency is dominating. Several respondents point to today's strictness in collecting loans, taking measures against cheaters, and hunting down those who try to be unreachable.

... that we've gone from having a great deal of concern for the client... that above all we encourage helping people and want to prioritize service... and there's no end to it... to a situation with a whole lot of 'the money must be paid back,' 'Wrong payments may never occur,' eh, 'hunt cheaters all over the world'...//... There's clearly been a shift in culture which quite a lot of people have had greater or lesser problems with. Because it hasn't felt like... well, we've lost our concern for the client, they've put in more of this stuff about: So, what does it mean to be a public servant? Well, you're actually handling the citizens' money and you should protect it. (Lennart, top manager, many years in service) 
This change of priorities is reflected in the official catchwords of the authority. As one of the first signs of 'a new era,' the concept of 'customer' was introduced at the end of the 1980s. The official catchword then was 'A reckless investment in service.' A further step was expressed from 2000 onward: 'Loans shall be repaid.' As a kind of synthesis, today's catchword is somewhat more down-tuned: 'SBSS makes studying possible.' The transformation may be seen, though of course in a simplified way, as a journey from an institution for social support to a loan institute, and the latter term is often used in interaction with clients as a reason for not being able to fully consider the client's situation.

An important side of changes in commission profoundly anchored in the valuechange of the welfare state is the decreasing number of areas of support handled by the authority. In the 1980s and 1990s the student aid local offices were very much players in the development of local labor market policy. As such the authority had several different, sometimes parallel support forms and rule-systems to operate with, forms for supporting labor force re-education. This situation with many support forms and rule-systems in a way peaked at the millennium shift. At that time the Social Democratic government invested heavily in the so-called Kunskapslyftet (app. Knowledge lift)—an extensive investment program in adult education. This was a strenuous period for the SBSS, and the authority got a lot of bad publicity for too long turnaround times. In the aftermath of the program the role of SBSS was radically changed toward more of strict loan business specializing first and foremost on aid to students going through the regular higher education system. Thus, the number of alternative systems for aid decreased, and the ones left started to develop toward higher detailiation and regulative complexity. The role as labor market player was more or less abolished. At the same time efficiency in execution of customer cases was enhanced very notably, something that also has to be related to an organizational change heavily dependent on the introduction of new ICT on a broad scale.

\section{The impact of regulative development and new ICT on organizational change}

It is important to note that hand-in-hand with the change in commission toward a 'loan institute' goes the primacy of economistic values about cost-efficiency as the central aim for public service governance (Hood 1995). The overall efforts of rationalization and strivings toward productivity and cost-efficiency are clearly the basic aim behind changes in internal working conditions and organizational change in SBSS.

\footnotetext{
You can tell, you know... You can tell because... We get, we've got, less freedom, that is, we're not able to apply flextime on, when it's, under high pressure. We've had more to, well, we can't run faster, but we can do... Well we can work fast and efficiently, but we may not be able to do it faster, but we're supposed to do, the things we do, we're supposed to do more efficiently. If we can do, open one window with two mouse-clicks or less, then we should do it... (Tommy, 5 years in service)
}

Of great importance concerning the organizational development of SBSS is that it was established as a single authority in 1991 out of 24 local authorities for support of adult education, six student aid authorities, and one central authority for advice and surveillance. However, despite efforts to integrate these different local office cultures and work practices 
a certain heterogeneity lived on for several years, partly because of the above-mentioned existence of a division of labor based on the different parallel systems for aid to administer, partly because local managers were able to maintain a great deal of autonomy to develop their local office organization. Local offices mostly worked toward their own region in the decades before the millennium shift. As mentioned, they were often working together with other local authorities such as the employment agency, the social insurance office, municipalities, and the university. This meant that officials often attended dialogue meetings with study counselors, employment officials, and so forth trying to solve issues of support for individual applicants. When cases of student aid applications could not be treated in a routine way the official usually met the applicant face-to-face. To solve such cases by phone conversation was utterly rare. However, changes started to grow successively with the implementation of both new technical devices (e.g., computers) and organizational solutions (e.g., phone answering hours).

Today centralization of the authority has gone much further and work organization is radically different. Business is run by telephone, e-mail, and IT/Web independent of local anchoring in offices. The latter have become a kind of historical remnant. Local receptions are closed down. Every office is specialized on one or sometimes two types of tasks (e.g., repayment of loans, loan applications) working on a national scale; 80 per cent of applications for student aid are automatically processed. From 2012 all applications are done via the Web, no paper forms are used anymore. Most measures are expected to be taken by the web-savvy customers themselves. Customer alternatives for contact are e-mail and telephone. Phone calls go initially to the front office. The vast bulk of these are handled by the Call Center. Those are normally about general information, giving help with easy questions. The more complex calls go to officials with special competence in back office. Because local offices are responsible to back-up the Call Center taking front office calls every official occasionally has to do a couple of hours' duty in the front office position besides a couple of hours in back office position. This means a normality of 2-4 hours phone work per day. In periods of high customer pressure the phone shifts may be doubled. The main activity besides phone work is to administer and investigate customer cases. Even though decisions in individual cases are in the end taken by one single officer, several officers may be involved, taking minor steps during the process of investigation. Every case is open for every official, and when applicants phone up they are connected to whichever official is available. In several cases the official recently had to consult the 'specialist' before deciding. Specialists were colleagues on local office level with extra and deeper competence in the field. In difficult cases officials also could get help from a support unit at Head Office. However, in the new ongoing organizational change both local specialists and the support unit have disappeared. Finally, clients are able to appeal decisions at The National Board of Appeal for Student Aid, which has jurisdiction to abolish SBSS decisions. A growing number of precedent-setting cases from this board contribute to an increase in regulation.

\section{Officials: a de-coupling from the local context and a de-personalized relationship with clients}

As described in the previous section managers as well as individual officials in 'the old days' used to have space for taking part in local processes, working out collaborative 
agreements about local labor market ventures besides working with individual cases. In this case for example, and especially for local offices occupied with adult education (originally 24 out of 30 offices), it could be about re-education of a certain individual or group of workers becoming un-employed because of a factory closing down. The role of the officials here was to help finding solutions in the different rule systems for the attendants' financial support. All in all, the more intricate individual cases of student support were always solved in close co-operation on a local level. In the case of a student that had not reached the stipulated university points for getting further financial support for instance, decisions were taken in dialogue with a study counselor. How to handle a student with problems of re-paying a loan was often decided in dialogue with a social secretary.

\begin{abstract}
It's been like that for, it's been like that, well, for, for a very long time, maybe since before 2000 roughly. Back then, we had a consulting group together with representatives from the university, back then we were called $\mathrm{X}$ university. We had consulting groups and for a while there we also had one for municipal adult education students, but that wasn't quite in the same way. Then, it was with some study counselor, some welfare officer and it was preferred, not that they had any right to decide, because that was still up to us, but they could add their... (Anne, 24 years in service)
\end{abstract}

This quote has two important implications in relation to competence and discretion. First, personalized local networks of officials with different jurisdiction and competence enhance the space for influence and power. Second, together with a much more 'loose' regulation the possibility to know and act upon all 'facts' in unique cases was bigger. Today however, geographical location has nothing to do with work performance. A decoupling from the local context is here an aspect of a more general de-personalization of the relationship with clients (and other external actors). An earlier type of client work with elements of personal relation building has now been replaced by superficial and de-personalized relations for efficient service delivery to anonymous customers. Officials use computer technology and telephone communication as working tools. On the one side this means being tied physically to working in stations with computer screens and telephone headsets. On the other it means being dependent on web-based information, investigation tools, and web forms. A phone conversation starts with the official loggingin to the customer's personal web page, reading facts in the case before being able to discuss it. This reading is necessary due to the lack of relationship, and because measures may have been taken by other officials. The strategy behind the use of ICT here is obviously about making knowledge accessible and usable throughout the whole organization. Making the investigation process in every single case 'open' makes the customer independent of single officers. Every official available may take decisions in the process. That several officials may be involved in this way does not mean taking decisions in dialogic networks. It means, however, that they often must check up, and take decisions on the basis of work done by colleagues. Further, that different officials make contributions in the processing of individual cases makes each official more distant to the unique client, than if cases were referred to and handled by one and the same official (direct phone numbers are not normally given to clients). This restricts the possibility to 'see' and consider special conditions, and it may strengthen clients' views of officials as faceless bureaucrats. On the other hand, some clients may value the efficiency of not having to 'hunt down' a particular officer in order to get their case dealt with. Most respondents 
do not seem to perceive this as a problem in the relationship with clients. However, what becomes clear from a lot of our audio recordings is that several customers/clients get irritated when having to recapitulate and explain their situation to a 'new' official 'on and on.' Together with the front- and back office system this may trigger feelings of being bounced between different officials. And, it is a strong indication of the fragmented relationships that prevail nowadays between officials and their customers. Besides being a target for this kind of irritation several respondents pointed to the satisfaction and experience of meaning in work when they get the time, decisional space, and ability to help a customer in a tough and complicated situation:

I: Which of your tasks do you find most rewarding then? What, what's most fun to work with?

R: That's probably, well, it sounds horrible, but the ones who have difficulties paying (laughs).

I: Oh, okay. No, that's not horrible at all, if you think about it.

R: But to try to, that one can help and how one can make things easier and what, what one can do to... Maybe not paying that much or divide it or... that it's not impossible, that one can help. (Kristina, 7 years in service)

A final aspect of de-personalization is the ICT in itself. Simply using e-mail and telephone to interact with customers, rather than meeting physically, creates distance and reification of the other in relations. This has been thoroughly outlined by several sociologists (Collins 2004: 47 pp., Turner 2002).

\section{Automatization-standardization of work via technology}

As mentioned previously, all applications are done by the applicants themselves via the Web. The vast majority of applications are processed automatically. The driving force behind is of course higher cost-efficiency. However, it also may be assumed as contributing to job enrichment because officials are being liberated from sorting, registration, and classifying simple cases. Most respondents do not seem to miss the handling of un-complicated applications. However, some say that performing simple routine work now and then gives opportunities to relax, and that it counteracts stress. Obviously automatization also creates some worries about vulnerability, de-personalization and future staff reduction:

I: Do you see any disadvantages then, with the automatization?

R: Yes, if it becomes too automated, of course, fewer officials might be needed. Also, it becomes rather impersonal and we become quite vulnerable, in case there's trouble with the computer.

I: Yes, if there's trouble...

R: We'll be very vulnerable if there's too much automatization and not enough staff. That's what I think. (Lena, 7 years in service)

However, there is an interesting paradox here: the automatization of processing simple cases leaves only the complicated and challenging ones for officials to handle. At the 
same time though, ICT is used to standardize the work process in these latter cases. Obviously tools and technical support systems (forms with squares and limited numbers of alternatives that lead the investigator, mathematic devices that help counting, and so forth) make the instrumental side of work faster. These tools standardize work and circumscribe alternative investigator decisions. ICT use in SBSS is a clear example of codification-storing knowledge, converting intellectual property into structural capital. A precondition for this is a regulative framework that narrows down investigator discretion. This is felt by respondents:

R: Unfortunately it'll become much more regulated. We won't have the same ability to act as we've had before and... There will be clearer guidelines and more boring guidelines.

I: Stress as well?

R: Well... Well I don't know, but above all there will be more routine-...

I: Routine tasks. That's a bit of a paradox, if they at the same time, just when you've got rid of those real routine tasks...

R: Yes, exactly. (Tommy, 5 years in service)

Thus, automatization means removal of simple routine business. Only the more complicated cases, those that demand more of skill and knowledge remain. However, the recent development indicates that the processing of these becomes more routinized because of 'codification' and increasing detailed regulation.

\section{Centralization—standardization of work via increased detail in regulation}

The former era of parallel and often quite vague rule systems has now come to an end. Significant of today's regulative system is that it is a uniform and integrated one continuously growing in detail to encompass all possible types of alternative solutions that may be of actuality in different cases. Hand-in-hand with this goes a centralized control of how the system is applied in practice made possible by different ICT measures (see below). A former quite decentralized organization in the 1990s with quite extensive local office autonomy has become centralized. Today what remains of such local autonomy are some questions about internal organization and staff recruitment, and even this is decreasing.

...what they do operatively is strictly managed. There are regulations for how many emails one should handle, how many calls one should take, what type of cases one should do, in what order one should take the phone shifts, there are directives about all this stuff. (Lennart, top manager, many years in service)

The increasing detailiation complemented with distinct instructions for each type of case narrows the scope for officials to evaluate and take action on the basis of a welldeveloped knowledge of the complexity of unique cases.

In July 2010 the rules became more rigorous, when it comes to examining results, yes (for the right to get support and loan, my remark). And it was then that it all became more rigorous, that you needed certificates, that is, it should be correct in terms of time and that 
we should only look at their latest period of receiving study aid. Before that we could go further back in time and check, if their average was okay, that meant it was a temporary slump and we were content if the prognosis looked good, that something had happened and they, people felt better and one could assess... But now it's just, well, one checks: Has something happened and what's happened and is it verified, period. So it's, it feels a bit cynical, somehow, in my opinion. (Anne, 24 years in service)

This quote also highlights how the concept of service is understood and applied in SBSS today. Giving good service is not about good personal meetings, listening-in, and considering unique aspects of unique cases. It is about quick answers to give the customer all available alternatives to choose among, if there are any. All officials shall act in the same way. To consider individual deviations is a threat to the safety of uniform treatment.

The rigorous regulation of today and the decrease of parallel rule systems do not seem to be experienced by officials as easier to handle, clearer, and more manifest maybe, but not easier. In combination with different control measures it also seems to be creating a kind of unsafety to act, i.e., a fear of doing the wrong thing. Even management seems to experience that an increasing number of directives and a growing detail in regulation may lead to lack of safety in the occupational role:

H... instead things have developed in such a way that we've come this far in the quality assurance work and have cut back when it comes to assuring the quality of the actual rules and regulations, instead it has... instead you get the feeling that it might have inhibited the administrators when it comes to thinking more freely.

C. They don't dare make decisions.

H. They've become so controlled by wanting to do things the right way. (Hedvig and Carin, HR Managers)

Hand-in-hand with automatization and regulative detailiation goes a decreasing amount of opportunities for exchange of experiences and knowledge in collegial dialogue (cf. Lopéz-Nicolas \& Meronõ-Cerdán's (2009) concept of personalization of knowledge above). Arenas for local and collegial support, discussions and consultations, group sessions, and so forth, about tricky cases has almost disappeared:

No, not anymore. Before we had joint, even if it was the specialist who made the decision, together with an administrative official, we had joint meetings where we discussed things... But that was probably before the rule system became more regulated, because the only ones, we handle mostly in this result examination, that's the ones who don't have sufficient study results, and, and that's so strict nowadays, so there's not as many possibilities, as there used to be,. (Anne, 24 years in service)

So, even if officials work with 'open cases,' i.e., different officials may take action in the same single cases during the process, they work very much in isolation from each other nowadays. The lack of collective support in developing work practice can be seen as another decrease in discretion as well as a loss of quality in work because it deprives them of abilities to deepen their knowledge by sharing experiences with others (cf. Amble 2013). 


\section{Increased openness for monitoring and control of work performance}

No doubt the Web and the intranet provide tremendous opportunities for controlling and integrating the workflow in the organization. Information, rules, and regulations are accessible to both staff and clients. All steps taken by individual officials are open for monitoring by management. The kind of unsafety in case handling discussed above must of course be understood also in relation to this. Officials seem fully aware of the transparency of their work:

R: Yes (laughs). But sure, sometimes you wonder, being controlled all the time and they know exactly what you do and for how long you're on a break after a call and how many cases you've done, because it's measured all the time, and, and then they say 'Yes but we don't look at that, we only look at groups,' but...

I: Yeah, because they compare offices.

R: Yeah, but then you hear, when people talk, that you can't know certain things unless you've been in to check up on the individual (laughs) so it, it happens and it's probably been like that everywhere but it... Then again, I don't know, as long as I don't have anything to hide I guess they can look (laughs). (Lena, 7 years in service)

Officials take decisions about quite large sums of money, and they know that every step they take is open for control by management and other officers. This creates a self-disciplinary way of always checking up on measures taken by themselves and other colleagues, re-counting sums calculated by the computer, and so forth. This kind of selfcontrol guarantees correctness and uniformity (isomorphism) in case handling. At the same time though, it may create insecurity and inefficiency, something that can be quite annoying even for management:

...while we've ended up in an investigation culture that sometimes, how should I put it,.. is counterproductive because, to many people, investigation means checking. I check with a colleague, I check the system, I check once again that my calculations are correct... which makes it... when we think of an investigation we think, well I'm performing an evaluation and make use of the mass of information to reach a decision. But it often ends up being a question of 'Suppose I check this' 'now I've checked that' 'and now I've checked that'... it's like there's a kind of a mismatch about the image of what it means to investigate. So we're working quite a bit with training in investigation methodology and case-handling templates and investigation templates and all kinds of things. (Lennart, top manager, many years in service)

\section{Governing work via quality measures and performance indicators}

The authority uses a great number of follow-up measures to gain information about organizational performance. Annual reports reveal a multitude of operative goals (e.g., maximum three minutes in the telephone queue, a maximum of three weeks processing time for each case, 70-75 telephone calls per day at the call center, etc.). Results are evaluated through tight follow-ups (e.g., number and types of decisions, economic results, etc.). An extensive yearly survey also investigates customers' rate of satisfaction with 
service. Other quality measures include managers listening-in on officials' telephone interaction, manager-co-worker developmental dialogues, case evaluation improvement seminars, and recurrent risk assessment.

The multitude of performance targets are, as mentioned above, according to management, only goals at organizational and local office level. However, this has resulted in some heated discussions between offices concerning different arguments of quantity versus quality. Criticism is directed toward Head Office for only presenting how many cases are dealt with in each office, how many are pending, and so forth. Especially staff at local offices with weak quantitative results in these comparisons (e.g., case handling) raises claims about the need to look into cases to evaluate the quality in processing. An answer from management concerning this type of criticism has been suggestions about developing measurement further.

... and this has spurred the employer to say 'Alright, now we must measure everything,' and then it's underway...//....... But then they say 'okay but now we must help individuals,' we can need help. In order to get competence development and support, personal performance must be measured. So now we're at that level. (Kurt, union representative 30 years in service)

Several respondents expressed worries that such tight following up sooner or later will reach individual level.

R: They don't measure time sequences now and they don't keep track on how many cases someone does per person, like that, but it is underway. I don't have a problem with it, so to speak, I think it could be a good thing to see, if there's... The thing is, there could be people who do two cases a day, or per hour, but they do them brilliantly, and then there may be a person who... does seventeen cases per hour, but who makes fifteen mistakes (laughs). If we had, or sixteen mistakes, that's not, very good, that's not good. So to find a solution, how one should work, it might be good, but... Now we have less freedom, so to speak, in terms of, stuff, and it has become more regulated, how one should do, when one is allowed to leave, when one, those things, that... One feels like, don't you trust us to do our job? (Tommy 7 years in service)

\section{Development of staff}

It should be emphasized that initiatives of educational efforts are mostly taken on local manager level, with the HR department in an advisory and supportive role position. Differences between the numbers of local office initiatives for competence development have until today been quite large. Roughly speaking, management tries to develop the skills of officials along two lines. The first is to make the single officer a skilled service provider (via quality measures). Here, tools used are the above-mentioned manager listening-in on telephone calls, management-co-worker dialogues, etc., types of initiatives very much depending on aspirations among local managers. The second is to in accordance with task specialization develop officials' competence on regulation in their special field of competence. 


\section{A new GD and a new large-scale organizational change}

In 2011 a new GD took office. After a period of investigation she initiated an extensive process of organizational change starting in 2012. One explicit goal of this still ongoing process is to accumulate enough capital for heavy investments in a new IT system for living up to government goals of service deliverance; to establish a more uniform and functional managing system; and to develop the work roles of coworkers in different parts of the organization. The latter concerns both development of competence and a change of work organization. An early result of this process of change has been the closing down of three local offices and a staff reduction from about 1100 to 900.

The continuing venture on ICT is aiming to further enhance automatization by opening up the system to an even greater degree than today for customers to handle their own cases in a less time-consuming way. Cases that cannot be handled in this way are expected to be very few in future. In relation to these few tricky cases, the GD wants to 'recreate' the investigator. She expresses dissatisfaction with how the work role of officials has gone through a de-generation in the last decade:

Lots of administration but not much investigation. If one should try to make a distinction. This doesn't mean that our officials can't investigate, but it is very much of ... administration today. We need...//...need to get a change there and we believe this very much affects work environment, possibilities for individual development and the like, that one can create more of actual... investigating instead of putting figures in ... tick off things in squares.

Working with only a few, more complicated cases and through the whole process will re-personalize the relation between the official and the customer, and it will raise the need for officials' competence.

Yes, I want to create working conditions where co-workers do more of what is...investigating, analyzing, ... in other words using their intellectual potential. And if so, some of them will need some development to be able to do this.

One step in increasing levels of competence in the organization is academization. From now on, an absolute condition for being employed as an official is a formal bachelor degree, however not a specific one. At the same time she announces extensive investments in competence development for already employed staff. A further step here is the specialization of both local offices and officials in only one area of work tasks and competence, instead of the formerly expected two.

It is clear that the vision behind the organizational change now being in its first phase is increased automatization. Case processes will to an even greater extent than today be handled by customers themselves via a more user-friendly and transparent ICT system. At the same time the new GD wants to develop customer service by professionalizing the position of officials making them able to increase quality in the more complicated cases where special expertise is needed. Involvement in team-based dialogues about how rules shall be applied in practice and making small inquiries followed up by initiatives for rule development and change will, if realized, probably lead to an increased task discretion. Time will tell. 


\section{Conclusive discussion}

In this article the changes of the occupational role of SBSS officials have been analyzed as a result of three important macro-level forces of change working simultaneously in later decades: the successive erosion of certain central values of a former welfare regime; the introduction of new principles for governing public businesses; and the breakthrough of new ICT on a broad scale.

Over a time span of two-three decades changes in policy and values forming the basis for this occupational role have meant a change from being one with strong elements of social support to being an administrator in a loan institute. This has also meant a deprivation of one, probably highly appreciated part of the former role-that of being a local labor market player in cooperation with representatives of other authorities and often on the basis of substantive relations with clients. De-coupling from a local context and the de-personalized relationship with clients' create reification and estrangement between officials and clients, something that with few exceptions is experienced as an impoverishment of job content (cf. Asgarkhani 2007, Collins 2004, Turner 2002).

NPM principles for governing public businesses implemented with the help of the powerful tools of new ICT are the means behind changes. The different control measures of NPM based on principles about detailed regulation, step-by-step quality checks, performance indicators, and tight follow-up of results would not be possible without the new technology. Automatization (Tummers et al. 2009), codification of information (Lopéz-Nicolas \& Meronõ-Cerdán 2009), being restricted to standardized forms and computer devices, and the different self-regulating mechanisms that come with the transparency and openness for control (Garson 1989), here stimulate the kind of 'isomorphic approach' in the processing of cases discussed by Barton (2008). At the same time an increased specialization is going on between groups of officials (and offices), i.e., only one type of tasks for each official. Automatization means rationalization: routine tasks being taken over by machinery. This has already resulted in reduction of staff. Most of the officials left probably appreciate the loss of such routine work thanks to ICT. However, at the same time, technology together with standardization and detailed regulation has meant a routinization of cases that still has to be handled manually. The room for qualitative assessments has decreased while demands on formal correctness and step-bystep following of detailed rules in investigations have increased. As the new GD states officials have become administrators instead of investigators.

What becomes obvious when following Taylor and Kelly's (2006) distinction between value, rule, and task discretion is that programmatic aims at political and managerial level have been successively narrowed. The supremacy of goals about economic efficiency narrows the space to act in accordance with for instance empowerment of clients in weak positions. Concerning rule discretion the number of systems regulating different alternative support forms has decreased considerably after the millennium shift. What is left, and what even may have increased to some degree is task discretion. First, because of increasing detail of rules, cases may in a way become more complicated. More aspects of the case have to be investigated. This may open up opportunities for skilled officials to manipulate decisions in single cases on a more technical level. Some respondents and several audio recordings of speech sequences bear witness about how officials by for example integrating repayment plans and merging different loans are able to lower the client's financial burden. Second, a rigorous rule-following may 
sometimes contradict being experienced as a good service deliverer by customers. This dilemma may sometimes create a space for flexibility, a space for bending rules in the name of good service. Third, ICT means possibilities of looking up big amounts of data in a short time. Quite likely this means an increasing control of all possible alternatives of action at hand (e.g., finding precedential cases, exceptions from certain rules). However, other things point in the other direction: the transparency of the ICT system used in SBSS work toward self-regulation and isomorphism in action, a fear of doing the wrong thing which also is likely to create a drag for taking new initiatives. And, the lack of collective dialogue and support in developing interpretations of rules and practical policies also narrows discretional scope. When interaction between colleagues is first and foremost taking place digitally in the way described here it seems to work more toward control and conformity than support for creative development.

All in all, the last two decades have meant increased routinization and decreased discretion for officials. In the backdrop of this development today's management strategy behind the ongoing organizational change becomes clear. More types of now routinized work tasks should be taken over by expanded and upgraded computer machinery. This is obviously an aim with the planned investments in ICT. However, there are always some complicated cases. These shall be taken care of by a smaller workforce of highly skilled and competent officials with capabilities of making well-grounded assessments. Hand-in-hand with automatization and a decreasing labor force one therefore may expect a professionalization of 'the ones left' - a re-skilling of their occupational role, at least in relation to the routinization that has taken place since the millennium shift. It will then be a professionalization toward expanded task discretion based on solid knowledge on rule technicalities in combination with social competence in giving service to customers, a professionalism developed on the basis of a bureaucratic logic closely connected to the stated organizational aims and needs of this public service organization (cf. Evetts 2011, 2013).

On societal level then-is the result of the above described development improved public service in the area of student aid? The answer to this question has to be related to the values guiding public service of today. Cost-efficiency and effective service/distribution of strictly defined loans, grants, and allowances are central in this neo-liberal context. In relation to this the answer should be 'yes.' Facts and figures point in the same direction; in all normal (un-problematic) cases the SBSS of today is very efficient in handling its tasks. Service to customers in this context shall be understood as based on instrumental rationality-fast and safe delivery of goods demanded. It is not about relational work and personal treatment-listening-in, being flexible, considering and adjusting to unique conditions. In all normal cases we may expect that clients/customers experience SBSS as an effective service deliverer. In relation to the more problematic ones however, some doubts may be raised. And, if we relate to nowadays down-tuned welfare values about equality, supporting 'the underdog,' stimulating labor market development, and so forth, the answer may be different.

\section{References}

Amble, N. (2013). Autonomy and control when working with humans-A reflection on sociotechnical concepts. Nordic Journal of Working Life Studies, 3(4), 45-61. 
Asgarkhani, M. (2007). Digital government and its effectiveness in public management reform. Public Management Review, 7(3), 465-487.

Barton, A. (2008). New labour's management, audit and 'what works' approach to controlling the 'untrustworthy' professionals. Public Policy and Administration, 23, 263-276.

Bejerot, E., \& Hasselbladh, H. (2003). Nya kontroll- och maktrelationer inom sjukvården (New relations of control and power in health care). Arbetsmarknad \& Arbetsliv, 9(2), 107-127.

Bezes, P., Demazière, D., Le Bianic, T., Paradeise, C., Normand, R., Benamouzig, D., Pierru, F., \& Evetts, J. (2012). New public management and professionals in the public sector. What new patterns beyond opposition? Sociologie du travail, 54, e1-e52.

Bruhn, A., \& Ekström, M. (2014). The application of rules in frontline interactions in the public sector: A multilevel analysis of the Swedish Board of Study Support. Submitted.

Christensen, T., \& Laegreid, P. (eds) (2001). New Public Management: The Transformation of Ideas and Practice. Aldershot: Ashgate.

Christensen, T., \& Laegreid, P. (2007). Transcending New Public Management. The Transformation of Public Sector Reform. Surrey: Ashgate.

Collins, R. (2004). Interaction Ritual Chains. Princeton: Princeton University Press.

Dahl, H. M. (2009). New public management, care and struggles about recognition. Critical Social Policy, 29(4), 634-654.

Ellis, K. (2011). 'Street-level bureaucracy' revisited: the changing face of frontline discretion in adult social care in England. Social Policy \& Administration, 25, 221-244.

Evans, T. (2010). Professional Discretion in Welfare Services-Beyond Street-level Bureaucrazy. Aldershot: Ashgate Publishing.

Evans, T., \& Harris, J. (2004). Street-level bureaucracy, social work and the (exaggerated) death of discretion. British Journal of Social Work, 34(6), 871-895.

Evetts, J. (2009). New professionalism and new public management: changes, continuities and consequences. Comparative Sociology, 8, 247-266.

Evetts, J. (2011). A new professionalism? Challenges and opportunities. Current Sociology, 59(4), 406-422.

Evetts, J. (2013). Professionalism: value and ideology. Current Sociology/Current Sociology Review, 61(5-6), 778-796.

Garson, B. (1989). The Electronic Sweatshop. New York: Penguin.

Heritage, J., \& Clayman, S. (2010). Talk in Action: Interactions, Identities and Institutions. Malden: Wiley Blackwell.

Hood, C. (1991). A public management for all seasons? Public Administration, 69, 3-19.

Hood, C. (1995). The new public management in the 1980s: variations on a theme. Accounting, Organizations and Society, 20(2/3), 93-109.

Höjer, S., \& Forkby, T. (2010). The influence of new public management in child protection in Sweden. British Journal of Social Work, 41 (1), 93

Johansson, R. (1992). Vid byråkratins gränser. Om handlingsfrihetens organisatoriska begränsningar $i$ klientrelaterat arbete (At the borders of bureaucracy). Lund: Arkiv avhandlingsserie 39.

Kvale, S., \& Brinkmann, S. (2008). InterView: Learning the Craft of Qualitative Research Interviewing. Los Angeles: Sage Publications.

Layder, D. (1998). Sociological Practice. London: SAGE.

Liebling, A., Price, D., \& Shefer, G. (2011). The Prison Officer. New York: William Publishing.

Liljegren, A. (2012). Pragmatic professionalism: micro-level discourse in Social Work. Eurpoean Journal of Social Work 15(3), 295-312.

Lipsky, M. (1980). Street Level Bureaucracy-Dilemmas of the Individual in Public Service. New York: Russel Sage Foundation. 
Lopéz-Nicolas, C., \& Meronõ-Cerdán, Á. L. (2009). The impact of organizational culture on the use of ICT for knowledge management. Electron Markets, 19, 211-219.

Melander, S. (2013). Kassakultur i förändring. Samspelet mellan organisationskultur och administrativa reformer på Försäkringskassan (Changing insurance culture. The interplay between organizational culture and administrative reforms in the Swedish Social Insurance Agency). Lund: Lund University Dissertation.

Power, M. (1997). The Audit Society. Rituals of Verification. Oxford: Oxford University Press.

Schedler, K., \& Scharf, M. C. (2001). Exploring the interrelations between electronic government and the new public management. In Schmid, B., Stanoevska-Slabeva, K., \& Tschammer, V. (eds), Towards the E-Society. Hingham, USA: Kluwer Academic Publishers.

Stenlås, N. (2011). Läraryrket mellan autonomi och statliga reformideologier (The teaching profession between autonomy and state ideologies of reform). Arbetsmarknad \& Arbetsliv, 17(4), 11-27.

Strauss, A. (1987). Qualitative Analysis for Social Scientists. Cambridge: Cambridge University Press.

Taylor, I. (2007). Discretion and control in education: the teacher as street-level bureaucrat. Educational Management Administration and Leadership, 35(4), 555-572.

Taylor, I., \& Kelly, J. (2006). Professionals, discretion and public sector reform in the UK: re-visiting Lipsky. International Journal of Public Sector Management, 19(7), 629-642.

Tummers, L., Bekkers, V., \& Steijn, B. (2009). Policy alienation of public professionals. Public Management Review, 11(5), 685-706.

Turner, J. H. (2002). Face to Face. Toward a Sociological Theory of Interpersonal Behaviour. Stanford: Stanford University Press.

Warhurst, C., \& Thompson, P. (2006). Mapping knowledge in work: proxies or practices? Work, Employment and Society, 20(4), 787-800.

Weber, M. (1922/1983). Ekonomi och sambälle (Economy and Society). Lund: Argos.

\section{End notes}

${ }^{1}$ The abbreviations here SBSS-SLB-NPM-ICT will be used throughout the article. In the same way I will use 'official' denoting the occupational group studied, and alternate between 'client' and 'customer' when talking about the person's official work.

${ }^{2}$ The project is funded by the Swedish Research Council. 